\title{
Análise técnica e econômica da captação e uso de águas pluviais em uma edificação com diferentes tipos de coberturas
}

\section{Cássio Reis da Silva ${ }^{1}$, Mateus Alexandre da Silva ${ }^{2}$, Marina Neves Merlo ${ }^{2}$ Michael Silveira Thebaldi ${ }^{2}$,*}

${ }^{1}$ Centro Universitário de Formiga. Avenida Dr. Arnaldo de Senna, 328. Água Vermelha. Formiga- MG, Brasil (CEP 35570-000).

${ }^{2}$ Universidade Federal de Lavras. Departamento de Recursos Hídricos e Saneamento. Campus Universitário. Caixa Postal 3037. Lavras-MG, Brasil (CEP 37200-900).*E-mail: michael.thebaldi@ufla.br.

Resumo. Os sistemas de aproveitamento de água pluvial são soluções sustentáveis que auxiliam no uso racional da água, conservando este recurso, com isto, objetivou-se com o presente estudo analisar a viabilidade técnica e econômica do aproveitamento da água pluvial para consumo não potável em uma edificação residencial localizada no Município de Formiga, Estado de Minas Gerais, Brasil, comparando as particularidades entre a captação em telhados convencionais, em estrutura de madeira e telha cerâmica, e em estrutura metálica e telha de aço, realizando o dimensionamento hidráulico e de materiais requeridos, efetuando a composição de custos e análise econômica dos sistemas de captação da água pluvial em ambos os tipos de coberturas. Foi utilizada, como objeto de estudo, uma mesma residência com coberturas diferentes, que geraram diferentes áreas e posições de captação. Pela análise de dados pluviométricos históricos do município, pôde-se estimar a produção média mensal de água pluvial. Além disso, foi estimada a demanda por água não potável, sendo possível, portanto, o dimensionamento do reservatório de armazenamento de água pluvial. Ao dimensionar o volume do reservatório, identificou-se que no telhado convencional em estrutura de madeira e telha cerâmica, o Método de Rippl é o mais adequado, enquanto no telhado em estrutura metálica e telha de aço, o modelo de cálculo mais conveniente é o Método Prático Inglês. Já a análise econômica foi feita por meio do Método de Payback Simples, constatando que o sistema de aproveitamento de água pluvial não é viável economicamente para as condições simuladas, sendo, entretanto, viável quando se refere à questão ambiental.

Palavras-chave: Hidrologia urbana; Instalações hidráulicas prediais; Saneamento.

Abstract. Technical and economic analysis of rainwater harvesting and use in a building with different types of roofs.
Recebido

$06 / 11 / 2019$

Aceito

$26 / 12 / 2019$

Publicado

$31 / 12 / 2019$

Acesso aberto

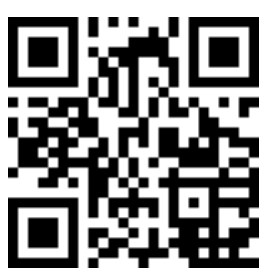

ORCID

(1) 0000-0002-1305-9103

Cássio Reis da Silva

(1) 0000-0002-2849-0668

Mateus Alexandre da

Silva

(D) 0000-0002-9518-6033

Marina Neves Merlo

(D) 0000-0002-4579-6714

Michael Silveira

Thebaldi 
Rainwater harvesting systems are sustainable solutions that help in the rational use of water, conserving this resource, thus aiming at the present study of technical and economic feasibility analysis of rainwater harvesting for non-potable consumption. in a residential building located in the Municipality of Formiga, Minas Gerais State, Brazil, comparing as technical particularities between capture in accessory roofs, wood structure and ceramic tile, and metal structure and steel tile, performing the hydraulic sizing and materials required, making a cost and economic analysis of rainwater catchment systems in both types of cover. It was used, as the object of study, the same residence with different coverage, which generated different water catchment areas and positions. By analyzing historical rainfall data of the municipality, it is estimated an average monthly production of rainwater. In addition, the demand for non-potable water was estimated, making it possible, therefore, to design the rainwater storage reservoir. When sizing or reservoir volume, it should be noted that there is no conventional roof in wood structure and ceramic tile, the Ripping method is most appropriate, while there is no roof in metal structure and steel tile, or the calculation model. most convenient is the English Practical Method. An economic savings made by the Simple Payback Method has already been analyzed, noting that the rainwater harvesting system is not economically viable for the simulated conditions, but it is viable when it comes to the environmental issue.

Keywords: Urban hidrology; Building hydraulic installations; Sanitation.

\section{Introdução}

Em escala global, o Brasil se encontra em situação estável quanto se trata de recursos hídricos (ANA, 2013). Apesar desta estabilidade, a distribuição espacial no território brasileiro é desigual. A maior parte destes recursos está concentrada na região Amazônica; em compensação, nas regiões Sudeste e Nordeste encontra-se uma menor parcela de água. Desta forma, percebe-se a necessidade da utilização de novas técnicas para conservação da qualidade e disponibilidade da água.

Segundo Gonçalves (2006), cerca de $40 \%$ do total de água consumida em uma residência é destinado a usos não potáveis. A substituição de água potável por água da chuva para usos não potáveis, é uma alternativa ao problema de escassez hídrica, e visa suprir a demanda da população em relação ao uso de água para fins não potáveis. A água pluvial pode ser utilizada em descarga de vasos sanitários, irrigação de jardins, lavagem de roupas, de calçadas e de automóveis, dentre outros. Com o sistema de captação da água pluvial é possível reduzir o consumo de água potável, minimizar alagamentos, enchentes, racionamentos de água e preservar o meio ambiente, reduzindo a escassez dos recursos hídricos.

A implantação de sistemas de captação de água pluvial exige um estudo aprofundado, tendo em vista que o não dimensionamento ou o dimensionamento não adequado destes sistemas podem acarretar superdimensionamentos dos materiais utilizados (destaca-se o reservatório por geralmente ser o item que necessita de um maior dispêndio) e cargas exacerbadas que exigiriam adequações estruturais ao sistema, podendo tornar a 
implantação do projeto economicamente inviável, ou até subdimensionamentos, onde o fornecimento de água é comprometido. Segundo Moruzzi et al. (2017) e Amorim e Pereira (2008) o dimensionamento do reservatório é uma etapa crucial do projeto, tendo em vista que é um item de alto valor, desta forma, determinante na viabilidade econômica.

Existem no Brasil e no mundo várias pesquisas e programas relacionados à implantação de sistemas de aproveitamento de água pluvial, para o uso racional e conservação da água em edificações, abordando principalmente novos conceitos de aproveitamento de água de chuva. Porém, poucos estudos tratam exclusivamente sobre implantação de sistemas de aproveitamento de água pluvial em diferentes tipos de cobertura.

Com isso, uma análise da viabilidade técnica e econômica do aproveitamento da água pluvial para consumo não potável em edificações com diferentes tipos de cobertura, possibilitaria comparar as diferenças técnicas entre a captação em telhados convencionais de estrutura de madeira e telha cerâmica e em telhados de estrutura metálica e telha de aço, conceber o dimensionamento hidráulico e de materiais requeridos em ambos os tipos de cobertura, e realizar a composição de custos e análise econômica dos sistemas de captação da água da chuva.

\section{Material e Métodos}

0 estudo foi realizado analisandose uma edificação residencial localizada no Município de Formiga, Estado de Minas Gerais, localizado a $832 \mathrm{~m}$ de altitude, com as coordenadas geográficas de referência $20^{\circ} 27^{\prime} 42^{\prime \prime}$ de latitude Sul e $45^{\circ} 25^{\prime}$ 58" de longitude Oeste (IBGE, 2010).

O objeto de estudo é uma residência na qual foi avaliada dois tipos distintos de cobertura; telhado convencional de estrutura de madeira e telha cerâmica; e telhado de estrutura metálica e telha de aço e suas vistas frontais são apresentados nas Figuras $1 \mathrm{e}$ 2 , respectivamente.

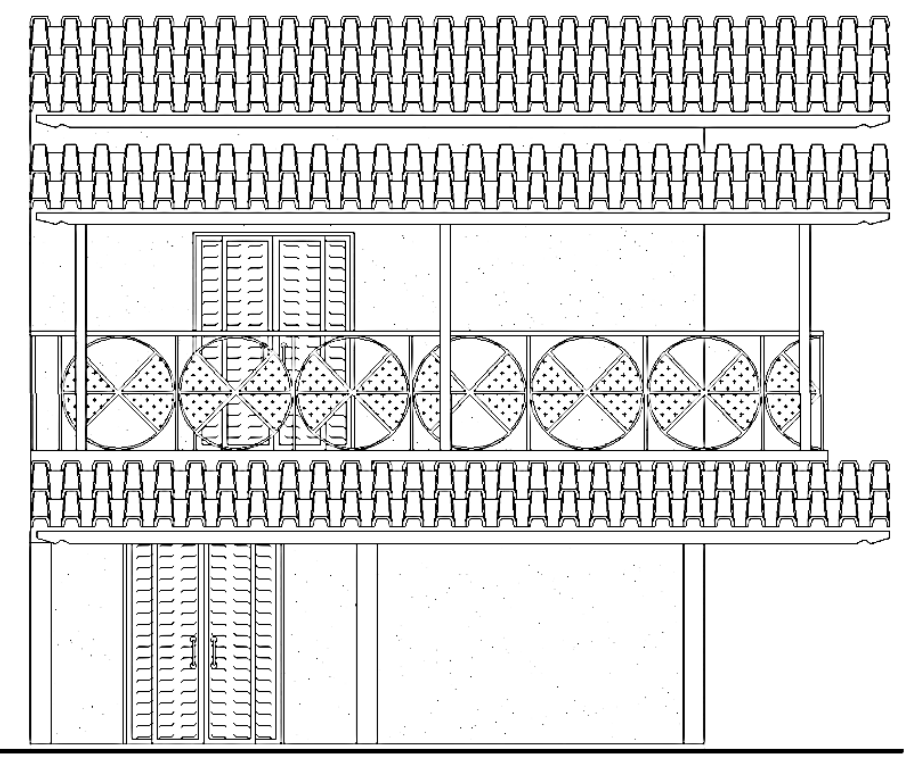

Figura 1. Vista frontal: telhado em estrutura de madeira e telha cerâmica. 


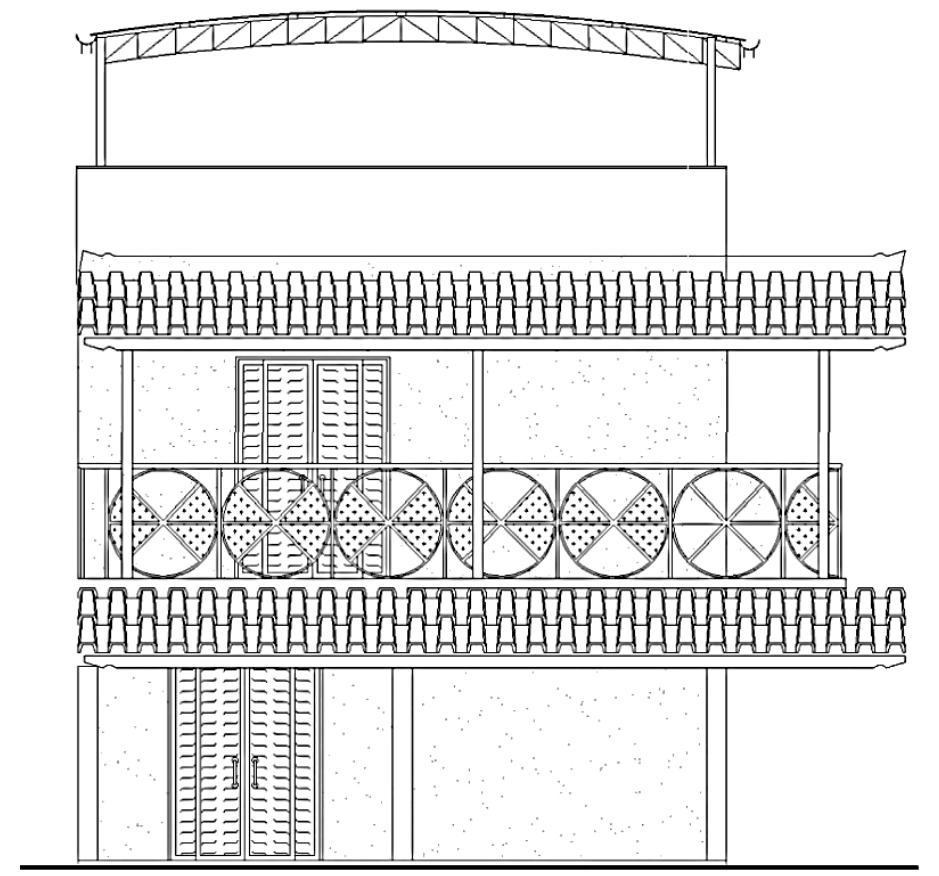

Figura 2. Vista frontal: telhado em estrutura metálica e telha de aço.

O cálculo da área de captação dos telhados foi realizado segundo 0 preconizado na norma ABNT NBR 10844:1989 (ABNT, 1989), baseado na planta de cobertura da edificação e inclinação dos telhados. A Tabela 1 apresenta o cálculo da área de captação de água pluvial nos diferentes tipos de telhados.

Tabela 1. Área de captação de água pluvial nos diferentes tipos de telhados.

\begin{tabular}{lc}
\hline Tipo de cobertura & Área $\left(\mathbf{m}^{\mathbf{2}} \mathbf{)}\right.$ \\
\hline Telhado convencional em madeira & 103,8 \\
Telhado em estrutura metálica & 66,5 \\
\hline
\end{tabular}

Considerou-se como área de captação apenas o telhado, por serem áreas mais limpas. Caso a água da chuva fosse coletada em outros locais, além do telhado, necessitaria de tratamento, mesmo sendo utilizada para fins não potáveis, em função de conter maior quantidade de poeira, folhas, insetos, além de outros resíduos.

Os dados pluviométricos foram obtidos através da página eletrônica HidroWeb (Sistema de Informações Hidrológicas), principal banco de dados com informações sobre os recursos hídricos, coordenado pela Agência Nacional de Água (ANA), compondo a Rede Hidrometeorológica Nacional, com 4.633 estações pluviométricas, onde são medidas as chuvas. Obtiveram-se os dados referentes às séries históricas de chuva no Município de Formiga. Com isso, por meio de uma planilha eletrônica, pôde-se determinar a precipitação mensal.

A Figura 3 apresenta os valores de precipitação média mensal para o Município de Formiga-MG, nos anos de 1925 a 1937 e 1976 a 2014. 


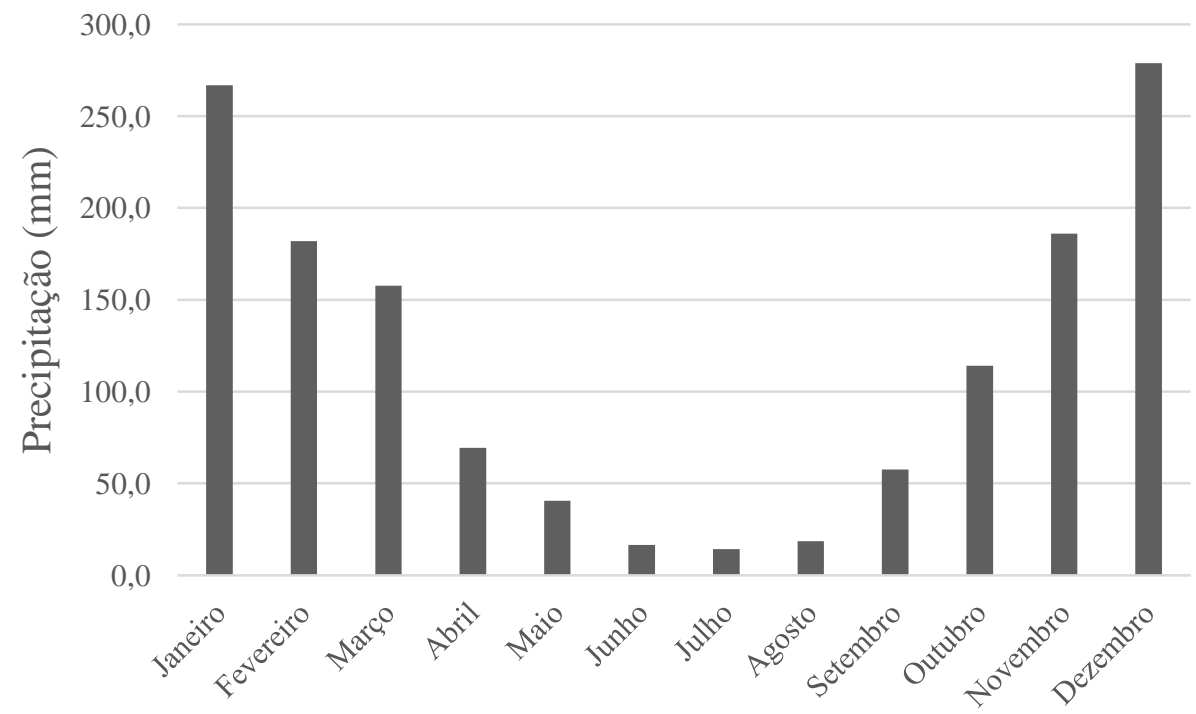

Figura 3. Precipitação média mensal de Formiga-MG nos anos 1925 a 1937 e 1976 a 2014.

Para calcular a quantidade de água pluvial a ser captada foi utilizada a

$$
i=\frac{K \times T^{a}}{(t+b)^{c}}
$$

equação de chuvas intensas Equação 1.

\footnotetext{
Em que:

i - Intensidade média da precipitação intensa, $\mathrm{mm} \mathrm{h}^{-1}$;

t - Duração da precipitação, minutos;

$\mathrm{T}$ - Período de retorno, anos;

$\mathrm{K}, \mathrm{a}, \mathrm{b}, \mathrm{c}$ - Constantes de ajuste locais.
}

De acordo com a norma ANBT NBR 10844:1989 (ABNT, 1989), o tempo de duração das chuvas deve ser fixado em $5 \mathrm{~min}$. Além disso, o tempo de retorno (TR) irá depender das características da área de captação. Como a captação da água da chuva foi feita em cobertura residencial, o TR será de cinco anos.
Para determinar os parâmetros de ajuste, foi utilizado o software Plúvio 2.1, elaborado pelo Grupo de Pesquisas em Recursos Hídricos da Universidade Federal de Viçosa (UFV, 2006). Os coeficientes de ajuste obtidos pelo software Plúvio 2.1 são apresentados na Tabela 2. 
Tabela 2. Parâmetros de ajuste para o Município de Formiga-MG, utilizando o software Pluvio 2.1.

\begin{tabular}{cc}
\hline Constantes de ajuste locais & Valor \\
\hline K & 1320,945 \\
A & 0,191 \\
B & 1474 \\
C & 0,808 \\
\hline
\end{tabular}

Fonte: Plúvio 2.1 (UFV, 2014).

Por meio da Equação 1, baseados nos parâmetros de ajuste apresentados na Tabela 2, obteve-se uma intensidade média máxima de precipitação para Formiga-MG, considerando chuva com tempo de duração de 5 min e tempo de retorno de cinco anos, de $161,34 \mathrm{~mm} / \mathrm{h}$.

A estimativa da demanda de água não potável da residência foi calculada

$$
\mathrm{Q}_{\mathrm{INT}}=\mathrm{Q}_{\mathrm{VS}}+\mathrm{Q}_{\mathrm{ML}}
$$

Equação 2

Em que:

$\mathrm{Q}_{\text {INT }}$ - Somatório das demandas não potáveis internas ( $\left.\mathrm{L} \mathrm{dia}^{-1}\right)$;

$\mathrm{N}$ - Número de habitantes da edificação.

$\mathrm{Q}_{\mathrm{vs}}$ - N x vol. de água do vaso sanitário x $\mathrm{n}^{\circ}$. de descargas ( $\mathrm{L} \mathrm{dia}^{-1}$ ); $\left(\mathrm{L} \mathrm{dia}^{-1}\right)$;

$\mathrm{Q}_{\mathrm{ML}}$ - $\mathrm{N} \mathrm{x}$ volume de água máquina $\mathrm{x}$ frequência de lavagem $\mathrm{x}$ coeficiente de carga

O presente estudo considerou na demanda interna apenas o vaso sanitário, considerando seis habitantes na residência e cinco descargas por habitante por dia. Não foi levada em consideração a lavagem de roupas.

Nas demandas externas, a água de chuva é utilizada para a rega de jardim, lavagem de áreas impermea- por meio da soma do consumo total diário, tanto para uso interno como externo, considerando o número de moradores ou usuários, sendo os valores mais usuais obtidos em Gonçalves (2006). A demanda interna não potável pode ser obtida por meio da Equação 2.

\begin{abstract}
bilizadas, lavagem de carros e na manutenção da piscina. 0 cálculo dessa demanda deve considerar, além da área e do volume de água, a frequência que os moradores costumam realizar as atividades. 0 somatório dos volumes de cada uso fornece o valor da demanda não potável externa conforme a Equação 3.
\end{abstract}

$$
Q_{\mathrm{EXT}}=\mathrm{Q}_{\mathrm{JD}}+\mathrm{Q}_{\mathrm{AL}}+\mathrm{Q}_{\mathrm{PISC}}+\mathrm{Q}_{\mathrm{LC}}
$$

\section{Equação 3}

Em que:

$\mathrm{QEXT}_{\text {ET }}$ Somatório das demandas não potáveis externas ( $\mathrm{L} \mathrm{dia}^{-1}$ );

$\mathrm{Q}_{\text {JD }}$ - Área do jardim x volume de água x frequência de uso $\left(\mathrm{L} \mathrm{dia}^{-1}\right)$;

$\mathrm{Q}_{\mathrm{AL}}$ - Área impermeável x volume de água x frequência de uso $\left(\mathrm{L} \mathrm{dia}^{-1}\right)$;

QPIsc - Área da piscina $\mathrm{x}$ volume de água $\mathrm{x}$ frequência de uso $\left(\mathrm{L} \mathrm{dia}^{-1}\right)$; e $\left(\mathrm{L} \mathrm{dia}^{-1}\right)$.

$\mathrm{Q}_{\mathrm{LC}}$ - Volume de água $\mathrm{x} \mathrm{n}$ o de vagas de garagem ocupadas $\mathrm{x}$ frequência de lavagem 
Para o cálculo da demanda externa considerou-se apenas a rega de jardim e a lavagem da área impermeável.
O cálculo das demandas totais para a utilização de água pluviais para fins não potáveis, foi feito através da Equação 4.

$$
Q_{N P}=Q_{I N T}+Q_{E X T}
$$

\section{Equação 4}

Em que:

$\mathrm{Q}_{\mathrm{NP}}$ - Somatório das demandas não potáveis $\left(\mathrm{L} / \mathrm{dia}^{-1}\right)$;

Q máquina de lavar roupa $\left(\mathrm{L} \mathrm{dia}^{-1}\right)$; e

$\mathrm{Q}_{\mathrm{EXT}}$ - Somatório das demandas externas de uma residência - rega de jardins, lavagem de carros, piso, calçadas $\left(\mathrm{L} / \mathrm{dia}^{-1}\right)$.

$\mathrm{Na}$ demanda interna obteve-se um valor de 180 litros de água gastos por dia. A área impermeabilizada apresenta $6,1 \mathrm{~m}^{2}$; considerando-se 4 litros de água para cada metro quadrado, e com uma frequência de uso de 12 vezes ao mês, chegando-se a um consumo diário 9,76 litros. 0 jardim apresenta área de $10 \mathrm{~m}^{2}$, sendo utilizado na sua rega, 3 litros de água por metro quadrado, com uma frequência de 12 vezes ao mês, chegando-se a um gasto diário de 12 litros.

A demanda externa totalizou 21,76 litros de água por dia. A demanda total da edificação é a soma da demanda interna e demanda externa. Os valores estão representados na Tabela 3.

Tabela 3. Demanda interna, demanda externa e demanda total da residência mensal.

\begin{tabular}{lccc}
\hline Mês & $\begin{array}{c}\text { Demanda interna } \\
\text { (Litros) }\end{array}$ & $\begin{array}{r}\text { Demanda externa } \\
\text { (Litros) }\end{array}$ & Demanda total (Litros) \\
\hline Janeiro & 5.580 & 674,6 & $6.254,6$ \\
Fevereiro & 5.220 & 631,0 & $5.851,0$ \\
Março & 5.580 & 674,6 & $6.254,6$ \\
Abril & 5.400 & 652,8 & $6.052,8$ \\
Maio & 5.580 & 674,6 & $6.254,6$ \\
Junho & 5.400 & 652,8 & $6.052,8$ \\
Julho & 5.580 & 674,6 & $6.254,6$ \\
Agosto & 5.580 & 674,6 & $6.254,6$ \\
Setembro & 5.400 & 652,8 & $6.052,8$ \\
Outubro & 6.580 & 674,6 & $6.254,6$ \\
Novembro & 5.400 & 652,8 & $6.052,8$ \\
Dezembro & 5.580 & 674,6 & $6.254,6$ \\
\hline Total & 65.880 & $7.964,2$ & $73.844,2$ \\
\hline
\end{tabular}

Após a coleta e determinação de dados, foi necessária a estimativa do volume de água de chuva a ser captada, a partir da área do telhado, do coeficiente de escoamento superficial e os índices pluviométricos da região. Para esta estimativa, aplicou-se a Equação 5. 


$$
\mathrm{Q}_{\mathrm{AC}}=\frac{\mathrm{A} \times \mathrm{P} \times \mathrm{C}}{1000}
$$

Equação 5

Em que:

$\mathrm{Q}_{\mathrm{AC}}$ - Volume anual, mensal ou diário de água de pluvial a ser captada $\left(\mathrm{m}^{3}\right)$;

A - Área do telhado $\left(\mathrm{m}^{2}\right)$;

P - Precipitação anual, mensal ou diária na região (mm);

C - Coeficiente de escoamento.

Para a estimativa da produção de água pluvial adotou-se em ambos os tipos de telhados 0,80 como o coeficiente de escoamento superficial. A Tabela 4 apresenta os valores do volume mensal de água pluvial a ser captada pelo telhado convencional de madeira e de estrutura metálica.

Tabela 4. Estimativa da produção de água pluvial mensal no telhado convencional de estrutura de madeira e telha cerâmica e de estrutura metálica e telha de aço.

\begin{tabular}{lcc}
\hline \multirow{2}{*}{ Mês } & \multicolumn{2}{c}{ Produção de água (Litros) } \\
\cline { 2 - 3 } & $\begin{array}{c}\text { Telhado convencional de estrutura } \\
\text { madeira e telha cerâmica }\end{array}$ & $\begin{array}{c}\text { Telhado de estrutura metálica e } \\
\text { telha de aço }\end{array}$ \\
\hline Janeiro & 22175 & 14201 \\
Fevereiro & 15105 & 9673 \\
Março & 13091 & 8384 \\
Abril & 5765 & 3692 \\
Maio & 3370 & 2158 \\
Junho & 1364 & 874 \\
Julho & 1186 & 759 \\
Agosto & 1528 & 979 \\
Setembro & 4780 & 3061 \\
Outubro & 9473 & 6067 \\
Novembro & 15442 & 9889 \\
Dezembro & 23173 & 14840 \\
\hline Total & 116453 & 74576 \\
\hline
\end{tabular}

Foi fixada uma lâmina de descarte da primeira chuva de $2 \mathrm{~mm}$.

$$
\mathrm{V}_{\mathrm{DES}}=\frac{\mathrm{A} \times \mathrm{D}_{\mathrm{ES}}}{1000}
$$

Para calcular o volume de água a descartar, foi utilizado a Equação 6.

\section{Equação 6}

Em que:

$V_{\text {DES }}$ - Volume de água a descartar, $\left(\mathrm{m}^{3}\right)$,

A - Área da superfície $\left(\mathrm{m}^{2}\right)$,

$\mathrm{D}_{\mathrm{ES}}$ - Descarte de chuva por metro quadrado de telhado, ficando a critério a escolha da quantidade de descarte (mm). 
Os volumes de água a serem descartados da primeira chuva, nos diferentes tipos de coberturas, são apresentados na Tabela 5.

Tabela 5. Volume de água descartado nos diferentes tipos de cobertura.

\begin{tabular}{lc}
\hline Tipo de cobertura & Volume (Litros) \\
\hline $\begin{array}{l}\text { Telhado convencional em estrutura de } \\
\text { madeira e telha cerâmica }\end{array}$ & 207,6 \\
$\begin{array}{l}\text { Telhado em estrutura metálica e telha de } \\
\text { aço }\end{array}$ & 133,0 \\
\hline
\end{tabular}

Cada tipo de cobertura gerou diferentes volumes de descarte, pois possuem áreas de captação diferentes. Em função dos volumes de água pluvial a serem descartadas, o descarte poderá ser feito por meio do filtro VF1, que é uma ótima opção para o descarte da primeira chuva, além de filtrar a água e de atender às diretrizes da norma $\mathrm{ABNT}$ NBR 15527:2007 (ABNT, 2007).

0 dimensionamento das calhas seguiu os critérios da norma ABNT NBR 10844:1989 (ABNT, 1989), Instalações Prediais de Águas Pluviais, assim como os condutores verticais e horizontais que compõem o sistema de instalação pluvial.

Já o volume dos reservatórios foi estimado utilizando os Métodos Rippl, Método Prático Brasileiro (Azevedo Neto), Prático Inglês e Prático Australiano, conforme metodologia de cálculo apresentada na norma ABNT NBR 15527:2007 (ABNT, 2007) para posterior verificação de qual método foi mais eficiente. Para a estimativa da produção de água pluvial através do
Método Prático Australiano, adotou-se como o coeficiente de escoamento 0,80 e $2 \mathrm{~mm}$ de interceptação da água que molha as superfícies e perdas por evaporação.

Foram realizados três dimensionamentos distintos para cada tipo de cobertura, utilizando somente a demanda interna (os vasos sanitários), somente a demanda externa (rega de jardim e limpeza da área impermeabilizada) e utilizando a demanda total.

A instalação elevatória foi dimensionada de acordo com a vazão de projeto (consumo diário), que baseia no bombeamento de água de um reservatório inferior para um reservatório superior ou para um reservatório hidropneumático.

Foi aplicada a Equação de Forchheimmer, Equação 7, para a definição do diâmetro do encanamento de recalque. Após a escolha do encanamento de recalque determinou-se o de sucção que é o comercial superior ao selecionado para o recalque.

$$
D_{r}=\mathrm{Kx}\left(\sqrt[4]{\frac{X}{24}}\right) x \sqrt{Q}
$$

\section{Equação 7}

Em que:

$\mathrm{D}_{\mathrm{r}}$ - Diâmetro de recalque $(\mathrm{m})$;

K - Constante - adotado 1,3 (Porto, 2006);

$\mathrm{X}$ - Número de horas funcionando (horas);

$\mathrm{Q}$ - Vazão $\left(\mathrm{m}^{3} / \mathrm{s}\right)$. 
Para definir a bomba a ser utilizada, foi aferida a altura manométrica, que se refere à altura geométrica de elevação, mais as perdas de cargas nominais e localizadas na sucção e no recalque. Depois de determinar os valores, selecionou-se a bomba mais apropriada de acordo com os catálogos de fabricantes nacionais.

Assim, para o sistema de bombeamento foi previsto apenas para 0 caso de cobertura convencional em estrutura de madeira e telha cerâmica uma vez que para o telhado em estrutura metálica e telha de aço não será necessária a elevação da água pluvial.

$$
\text { Payback }=\frac{\text { Investimento inicial }}{\text { Fluxo de caixa }}
$$

Os custos de implantação e operação do sistema de aproveitamento de água pluvial resumiram-se basicamente em custos com materiais e equipamentos e custos com mão-deobra. Deste modo, fez-se uma estimativa dos valores de materiais e equipamentos necessários, através de uma pesquisa de preço em pelo menos três lojas de materiais selecionadas aleatoriamente, e para compor o custo e foi feita uma média.

O custo da mão de obra foi obtido segundo as Tabelas de Composição de Preços para Orçamentos (TCPO, 2013) em conjunto com o Sistema Nacional de Pesquisa de Custos e Índices da Construção Civil (SINAPI, 2015).

\section{Resultados e discussão}

\section{Calhas e condutores}

Devido a maior área de captação do telhado em estrutura de madeira e
Os diâmetros encontrados no dimensionamento do sistema, foram de 20 e $25 \mathrm{~mm}$ para o encanamento de recalque e sucção respectivamente. 0 modelo de bomba escolhida foi a Bomba Schneider BCR - $20001 / 4 \mathrm{cV}$, com rotor de $106 \mathrm{~mm}$.

Depois de verificar o potencial de economia da água potável, verificou-se os custos para a implantação e operação do sistema de aproveitamento de água pluvial, e também foi analisado sua viabilidade econômica, seguindo o Método do Payback Simples, de acordo com a Equação 8.

\section{Equação 8}

telha cerâmica em relação ao telhado em estrutura metálica e telha de aço (Tabela 1), obteve-se maior estimativa de produção de água (Tabela 4) por escoamento superficial, consequentemente gerou-se uma maior vazão de projeto. Apesar deste fato, no dimensionamento da calha não se fez necessária a alteração de seu diâmetro, apenas a adoção de diferentes declividades (Tabela 6), fato este explicado pela necessidade de uma drenagem mais rápida para o caso do uso de telha cerâmica, para que não haja o transbordamento de água na calha.

Observa-se que para o telhado em estrutura de madeira e telha cerâmica obteve-se condutores verticais e horizontais de maior diâmetro em relação ao telhado em estrutura metálica e telha de aço, devido à maior vazão de projeto no primeiro tipo de cobertura. 
Tabela 6. Vazão de projeto e dimensão da calha semicircular nos diferentes tipos de cobertura.

\begin{tabular}{lccc}
\hline \multicolumn{1}{c}{ Tipo de cobertura } & $\begin{array}{c}\text { Vazão de projeto } \\
\left(\mathbf{L}_{\text {min }} \mathbf{- 1}\right)\end{array}$ & Diâmetro (mm) & $\begin{array}{c}\text { Declividade } \\
\text { (\%) }\end{array}$ \\
\cline { 3 - 4 } $\begin{array}{l}\text { Telhado convencional } \\
\text { em estrutura de madeira }\end{array}$ & 139,6 & 100 & 1,0 \\
$\begin{array}{l}\text { e telha cerâmica } \\
\text { Telhado em estrutura } \\
\text { metálica e telha de aço }\end{array}$ & 89,4 & 100 & 0,5 \\
\hline
\end{tabular}

Já na Tabela 7 podem ser encontradas as dimensões dos condutores horizontais e verticais dos dois tipos de cobertura.

Tabela 7. Dimensões dos condutores horizontais e verticais e declividade dos condutores horizontais para os diferentes tipos de cobertura.

\begin{tabular}{lccc}
\hline Tipo de cobertura & Condutores verticais & \multicolumn{2}{c}{ Condutores horizontais } \\
\cline { 2 - 4 } & Diâmetro $(\mathrm{mm})$ & Diâmetro $(\mathrm{mm})$ & $\begin{array}{c}\text { Declividade } \\
(\%)\end{array}$ \\
\hline $\begin{array}{l}\text { Telhado convencional em } \\
\text { estrutura de madeira } \\
\text { telha cerâmica } \\
\begin{array}{l}\text { Telhado em estrutura } \\
\text { metálica e telha de aço }\end{array}\end{array}$ & 100 & 100 & 0,5 \\
\hline
\end{tabular}

pluviais

Reservatórios de águas por diferentes métodos de

0 volume calculado dos

reservatórios utilizando a demanda total, dimensionamento para diferentes tipos de telhados são mostrados na Figura 4.

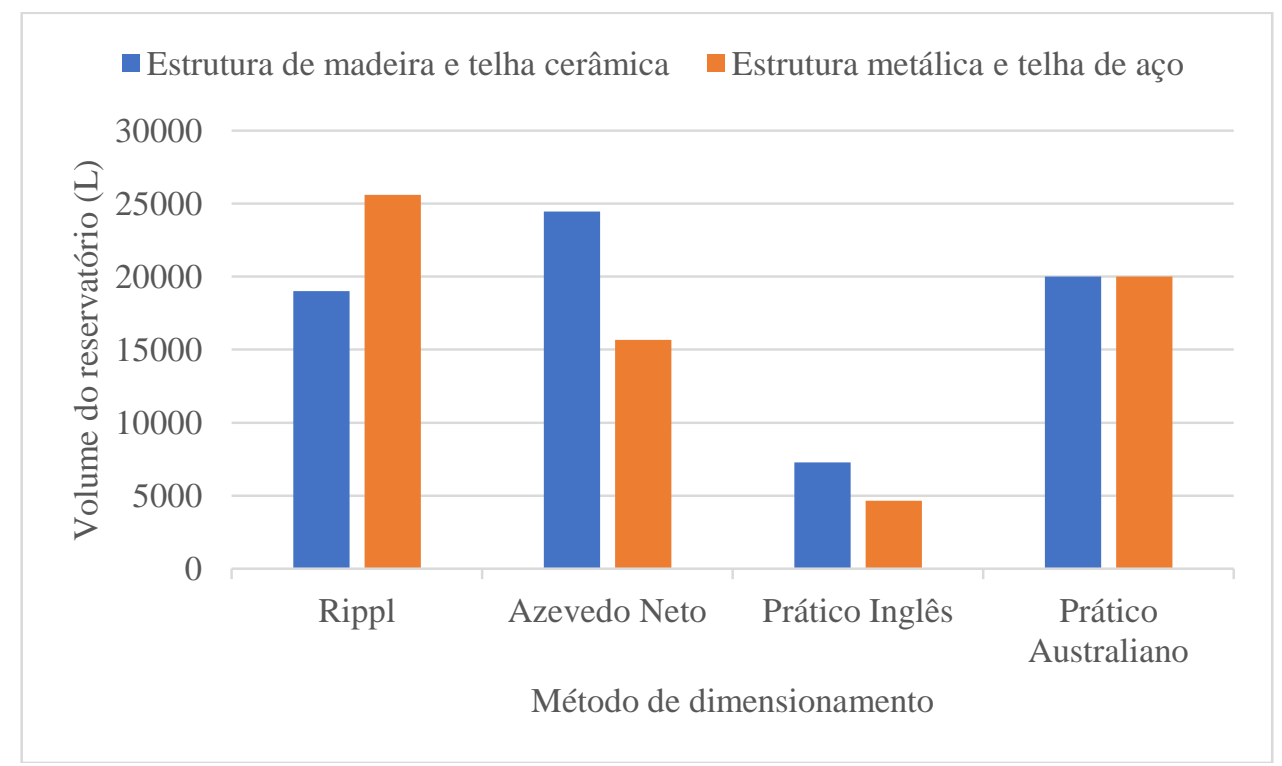

Figura 4. Volume dos reservatórios calculados utilizando a demanda total, por diferentes métodos de dimensionamento e tipos de telhado. 
O dimensionamento pelo método de Rippl neste estudo de caso, deu-se com a utilização de dados mensais.

Observa-se por meio da Figura 4 que utilizando o método de Rippl para dimensionamento, para o telhado em estrutura metálica e telha de aço foi gerado um reservatório maior em comparação ao telhado em estrutura de madeira e telha cerâmica. Este fato acontece, pois, o Método de Rippl é um método que regulariza a vazão, ou seja, como o telhado em estrutura metálica e telha de aço possui uma menor área em relação ao telhado de madeira e telha cerâmica, ele captará também menor quantidade de água, sendo assim o reservatório deverá ser maior para armazenar maior quantidade de água, suprindo os meses de escassez de chuvas.

Apesar do fato dos reservatórios dimensionados pelo Método Prático Australiano apresentarem o mesmo volume, a confiança obtida para o telhado em estrutura de madeira e telha cera- mica e o telhado em estrutura metálica e telha de aço foram, respectivamente, 100 e $50 \%$ respectivamente. A confiança maior atribuída ao reservatório dimensionado para o telhado em estrutura de madeira e telha cerâmica é devido a sua maior capacidade de captar a água da chuva, armazenando um maior volume em relação ao telhado em estrutura metálica e telha de aço. Segundo a norma ABNT NBR 15527:2007 (ABNT, 2007) recomenda-se que os valores de confiança estejam entre 90 e 99\%. Este fato indica que o Método Prático Australiano não é adequado para o dimensionamento de reservatórios para telhados em estrutura metálica e telha de aço que apresentem área de captação, índices pluviométricos e volume de demanda total iguais a deste estudo.

0 volume calculado dos reservatórios utilizando a demanda interna, por diferentes métodos de dimensionamento para diferentes tipos de telhados são mostrados na Figura 5.

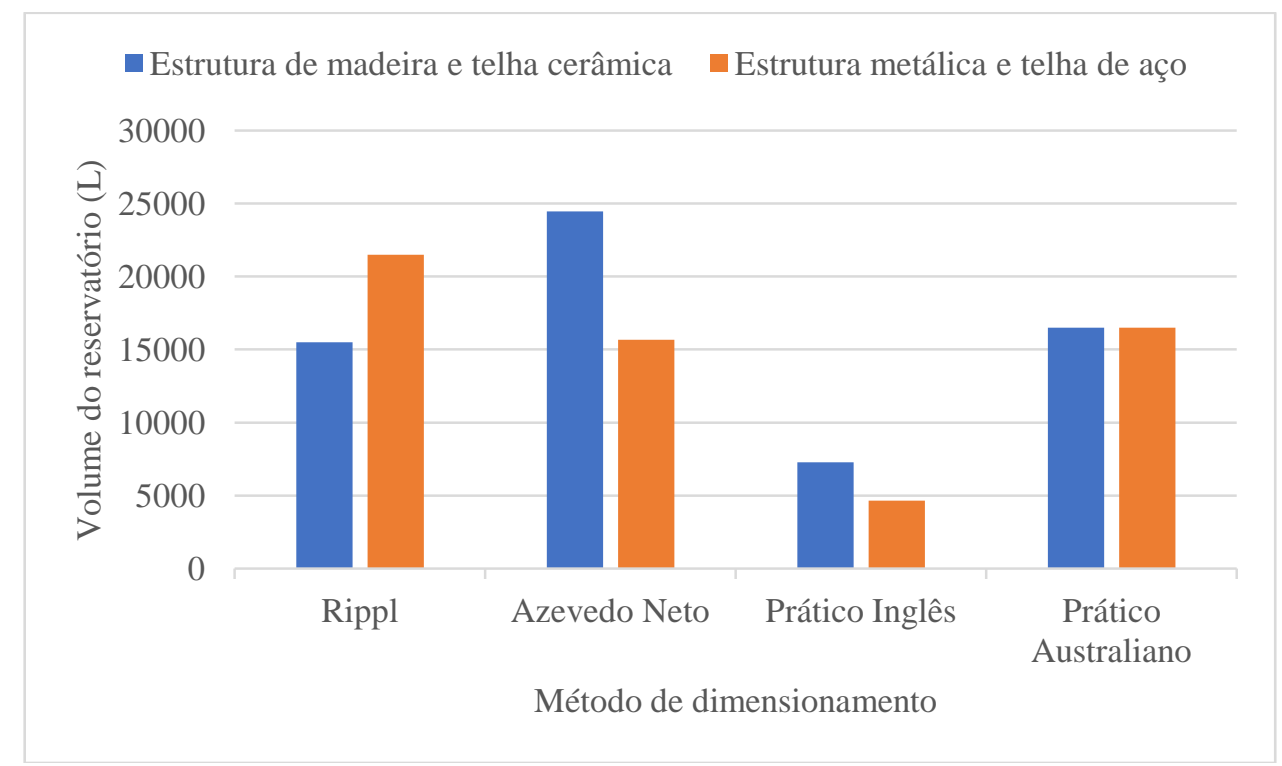

Figura 5. Volume dos reservatórios calculados utilizando a demanda interna, por diferentes métodos de dimensionamento e tipos de telhado. 
Como no dimensionamento da demanda total, no dimensionamento da demanda interna o Método de Rippl também apresentou maior volume de reservatório para o telhado em estrutura metálica e telha de aço. A mesma explicação pode ser aplicada, sendo a maior capacidade de captação de água responsável pela diminuição de volume do reservatório no Método de Rippl.

Apesar do Método Prático Australiano gerar o mesmo volume para o reservatório em ambos os telhados, a confiança obtida para o telhado em estrutura de madeira e telha metálica e para o telhado em estrutura metálica e telha de aço foram $100 \%$ e $66,66 \%$ respectivamente. A confiança maior atribuída ao reservatório dimensionado para o telhado em estrutura de madeira e telha cerâmica é devido a sua maior capacidade de captar a água da chuva, armazenando um maior volume em relação ao telhado em estrutura metálica e telha de aço. Segundo a norma ABNT NBR 15527:2007 (ABNT, 2007) recomenda-se que os valores de confiança estejam entre 90 e $99 \%$. Este fato indica que o Método Prático Australiano não é adequado para o dimensionamento de reservatórios para telhados em estrutura metálica e telha de aço que apresentem área de captação, índices pluviométricos e volume de demanda interna iguais a deste estudo.

0 volume calculado dos reservatórios utilizando a demanda externa, por diferentes métodos de dimensionamento para diferentes tipos de telhados são mostrados na Figura 6.

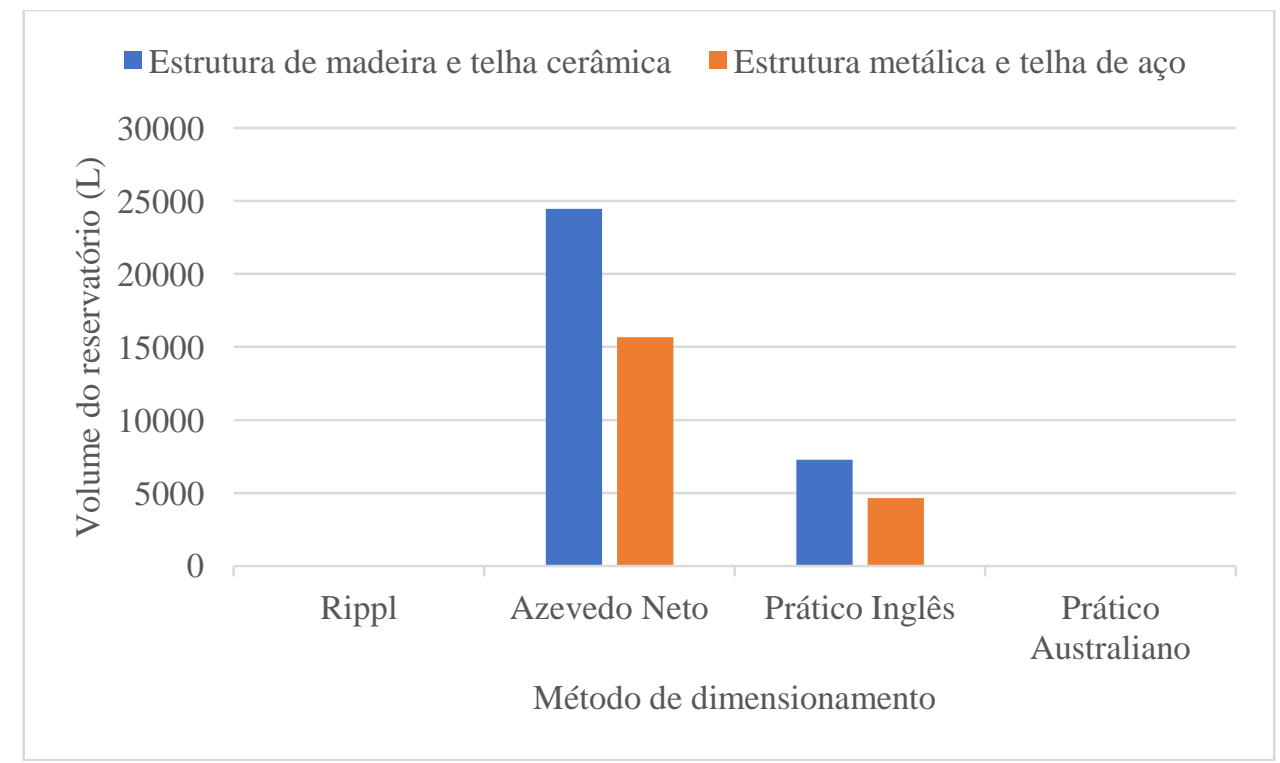

Figura 6. Volume dos reservatórios calculados utilizando a demanda externa, por diferentes métodos de dimensionamento e tipos de telhado.

Nota-se na Figura 6 que utilizando apenas a demanda externa no cálculo, não é possível determinar o volume do reservatório por meio dos métodos de Rippl e Prático Australiano para nenhum dos dois tipos de cobertura, pois ambos os métodos trabalham apenas com a hipótese que em algum momento o volume de água pluvial captada seria insuficiente para 0 abastecimento, necessitando assim de armazenamento para suprir os períodos 
de déficit. Com isso, constata-se que ambos os métodos não poderão ser empregados para o dimensionamento do reservatório, caso se utilize apenas a demanda externa apresentada neste estudo de caso.

Observa-se por meio das Figuras 4, 5 e 6, que os métodos Azevedo Neto e Prático Inglês apresentam volumes de reservatórios constantes apesar da variação da demanda. Este fato acontece, pois ambos os métodos desconsideram a influência da demanda de água pluvial nos seus cálculos. Por esta desconsideração, estes métodos podem estar sujeitos a falhas se os empreendimentos que serão contemplados com o sistema de captação de água pluvial apresentarem grande consumo de água não potável. Segundo Brandão e Marcon (2018), à medida que a demanda aumenta, a chance dos métodos Azevedo Neto e Prático Inglês gerarem déficit no abastecimento é maior.

Analisando as Figura 4, 5 e 6 juntamente às Tabela 3 e 4 constata-se que por meio dos métodos de dimensionamentos empregados, utilizando os diferentes valores de consumo de água pluvial que os reservatórios dimensionados para o telhado em estrutura de madeira e telha cerâmica por meio dos diferentes métodos atenderam satisfatoriamente a demanda, com exceção do reservatório dimensionado pelo Método Prático Inglês que atendeu apenas a demanda externa. Já os reservatórios gerados para o telhado em estrutura metálica e telha de aço, a partir dos diferentes métodos de dimensionamentos, atenderam apenas o abastecimento utilizando a demanda externa, pois a produção de água de pluvial em alguns meses do ano é insuficiente para suprir a demanda total e interna.

\section{Escolha do método mais adequado ao dimensionamento do reservatório de água pluvial}

0 dimensionamento do reservatório utilizando demanda total ou somente demanda interna ou somente demanda externa, foi necessária uma vez que, quanto maior o consumo de água pluvial, maior deve ser o volume do reservatório de acordo com o Método de Rippl e o Método Prático Australiano.

Já nos Método Azevedo Neto e Prático Inglês obteve-se volumes de reservatórios iguais mesmo havendo variação na demanda. Este fato ocorre pois, no dimensionamento realizado por meio de ambos os métodos a demanda não é considerada, mas sim a área de captação e o volume de chuva precipitado. Desta forma, quanto maior a área de captação e o volume de chuva precipitado, maiores serão os reservatórios obtidos por estes métodos, ou vice e versa, fato também encontrado por Brandão e Marcon (2018). O emprego destes métodos pode gerar reservatórios relativamente grandes, com custos maiores, sem necessidade. Podem também indicar reservatórios menores que não são capazes de atender à demanda, tornando necessária a utilização de um realimentador automático de água do abastecimento público na falta de chuva.

A escolha do método de dimensionamento a ser utilizado foi feita de acordo com viabilidade técnica de cada tipo de telhado. Para o telhado convencional em estrutura de madeira e telha cerâmica optou-se pela escolha do Método de Rippl. Já para o telhado em estrutura metálica e telha de aço, optouse pelo Método Prático Inglês.

O Método de Rippl foi o escolhido para telhado convencional em madeira, pois em todas as situações onde foi empregado atendeu a demanda. Brandão e Marcon (2018) também apontaram em seu estudo que os reservatórios gerados pelo Método de Rippl proporcionam garantias de abastecimento próximas a $100 \%$, visto que este método regulariza a vazão para suprir a demanda de água pluvial nos períodos mais secos.

Como no telhado em estrutura de madeira e telha cerâmica não é possível instalar o reservatório sob o telhado, este 
pode ser subterrâneo, necessitando de um sistema elevatório auxiliado por um sistema de bombeamento ou sobre o solo, podendo o reservatório ter a altura maior do que as outras duas dimensões, elevando a água por gravidade e dispensando o sistema de bombeamento. A instalação do reservatório fora do telhado, permitirá apresentar um volume de reservatório maior, sendo o Método de Rippl o ideal para dimensionar o reservatório deste tipo de telhado.

No telhado em estrutura metálica e telha de aço, optou-se pelo Método Prático Inglês, que apresentou menor volume requerido de reservatório e com isso, pode-se colocá-lo sobre a laje sem necessidade de implantação de um sistema elevatório com uso de bombeamento. Caso fosse adotado outro método de dimensionamento, não seria possível instalar o reservatório sobre a laje, pois o volume do reservatório seria elevado, tornando inviável sua instalação em uma residência convencional, sendo necessário um reforço na estrutural da residência, caso ela não tenha.

Portanto, mesmo que exista grande diferença entre os valores obtidos para o reservatório de armazenamento de água pluvial para os métodos analisados neste trabalho, a escolha do mais adequado deve ocorrer de acordo com os interesses finais de implantação de um sistema de aproveitamento de água pluvial e também em função da região de implantação. Em regiões com altos índices pluviométricos, deve-se escolher métodos mais conservadores, que levam a volumes inferiores para o reservatório, enquanto em regiões com baixos índices, o ideal é utilizar métodos que superdimensionem o reservatório, para que a água coletada nos períodos de chuva possa suprir a demanda nos períodos secos.

Alguns autores discutem sobre o dimensionamento dos reservatórios pluviais, como Amorim e Pereira (2008), que relatam que os métodos práticos, por serem menos complexos e de fácil aplicação, são mais indicados em residências unifamiliares ou em pequenos estabelecimentos, enquanto os métodos mais complexos, como o Método de Rippl, são mais adequados para projetos maiores, como indústrias. No entanto, não existe nenhuma restrição na aplicação de qualquer método a diferentes tipologias de edificações.

Já para Sacadura (2011), os métodos práticos, apesar de fácil aplicação, não representam a realidade de consumo para as diversas situações, podendo, contudo, aproximar-se da eficiência ótima em algumas situações, em que não vale a pena aumentar a capacidade do reservatório se esta não traz maior eficiência, mas sim maiores custos.

Fendrich (2009) afirma que os Métodos de Rippl, da Simulação, de Azevedo Netto, Prático Alemão e Prático Australiano, não são aplicáveis no dimensionamento dos reservatórios de aproveitamento das águas de chuvas, e que o Anexo A da norma ABNT NBR 15527:2007 (ABNT, 2007) deveria ser reformulado, exceto pelo Método Prático Inglês, com a ressalva de que sua construção seria antieconômica, e não incentiva os usuários a utilizarem tal sistema.

Brandão e Marcon (2018); Fendrich (2009) salientam que o Método de Rippl é utilizado na regularização de vazões, para dimensionamento de reservatórios de acumulação, onde a água captada no período chuvoso irá suprir a demanda no período seco. Segundo Fendrich (2009), o método de Rippl é geralmente empregado em captações para abastecimento público, em hidroelétricas, açudes, lagos paisagísticos e nunca sendo utilizado para dimensionamento de reservatórios de águas pluviais. Os reservatórios de aproveitamento das águas de chuva para fins não potáveis, baseados na demanda diária, mensal ou anual, assim, não são aplicáveis, sugerindo a utilização de seu próprio método, ou seja, o Método de Fendrich. 
Segundo Sperancetta et al. (2004), o Método de Fendrich foi desenvolvido para diminuir as enchentes provocadas pela impermeabilização do solo, fazendo com que cada logradouro reserve a água pluvial e, em seguida, utilize-a para a redução do consumo de água potável. Portanto, o reservatório deve estar sempre vazio para que possa receber a água da chuva, e então utilizála.

Ainda Giacchini (2010) ressalta que o Método de Fendrich não objetiva dimensionar o reservatório para o uso da água da chuva e, contudo, tal uso aconteceria em decorrência da detenção temporária da água pluvial. Dessa forma, a aplicação local do método condicionase às variações atmosféricas, não contemplando a continuidade do uso em períodos mais prolongados de armazenamento, tendo em vista a necessidade de manutenção do reservatório no estado vazio para novos eventos de precipitação pluviométrica.

Quando comparados os volumes de reservatório dimensionados em cada método com o melhor volume em termos do potencial de economia de água potável, Rupp et al. (2011) averiguaram que os Métodos de Rippl, e Azevedo Neto resultam em reservatórios maiores do que o ideal. Os volumes de reservatório obtidos pelo método Prático Inglês são superdimensionados nos casos em que a precipitação é alta, e subdimensionados quando a precipitação é baixa. Nos casos em que é possível utilizar o método Prático Australiano, os reservatórios também são subdimensionados.
Ainda para os mesmos autores, o Método de Rippl possibilita dimensionar os reservatórios de água de chuva somente quando há diferença positiva entre o volume e a demanda de água pluvial, ou seja, quando em algum momento do período analisado a demanda supera o volume. Pelo método Prático Australiano somente é possível dimensionar os reservatórios quando, em algum período, a demanda de água pluvial supera o volume mensal de água pluvial. Os dimensionamentos pelos métodos Azevedo Neto e Prático Inglês resultam em tamanhos de reservatório constantes para cada região, independentemente da demanda de água pluvial. Portanto, quanto mais alta for a precipitação da região, maior será o volume do reservatório.

\section{Análise econômica}

A Figura 6 apresenta os valores dos materiais utilizados na instalação e o custo total do sistema de reaproveitamento de águas pluviais para o telhado em estrutura de madeira e telha cerâmica.

É possível observar na Figura 6 que o item que gera o maior dispêndio é o reservatório. Para minimizar os custos da instalação de um sistema de reaproveitamento de água pluvial é necessário que o dimensionamento do reservatório seja feito de forma cuidadosa, evitando superdimensionamentos que podem inviabilizar economicamente o projeto. 


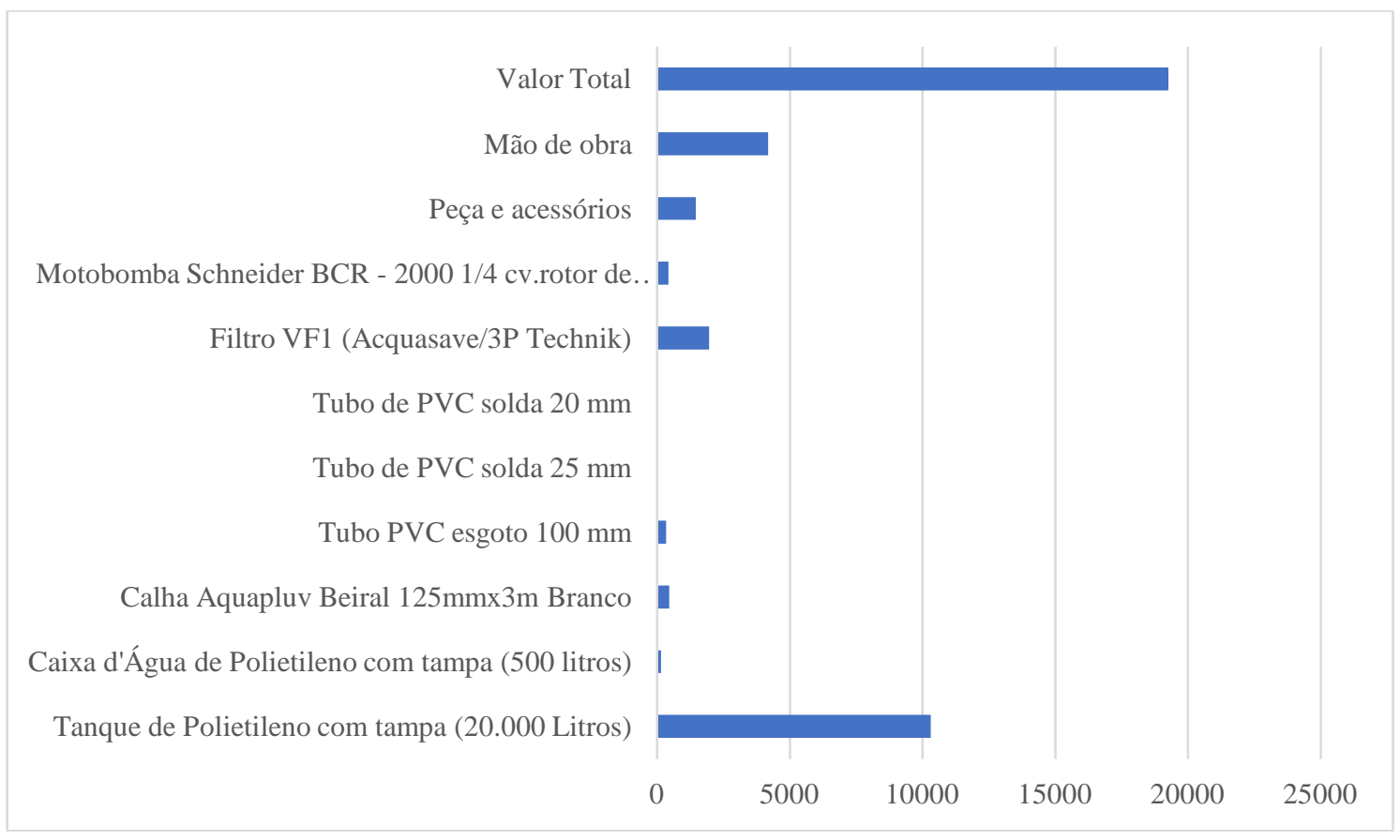

Figura 6. Custos dos materiais e total para instalação do sistema de reaproveitamento de água pluvial no telhado em estrutura de madeira e telha cerâmica.

A Figura 7 apresenta os valores dos materiais utilizados na instalação e o custo total do sistema de reaproveitamento de águas pluviais para o telhado em estrutura metálica e telha de aço.

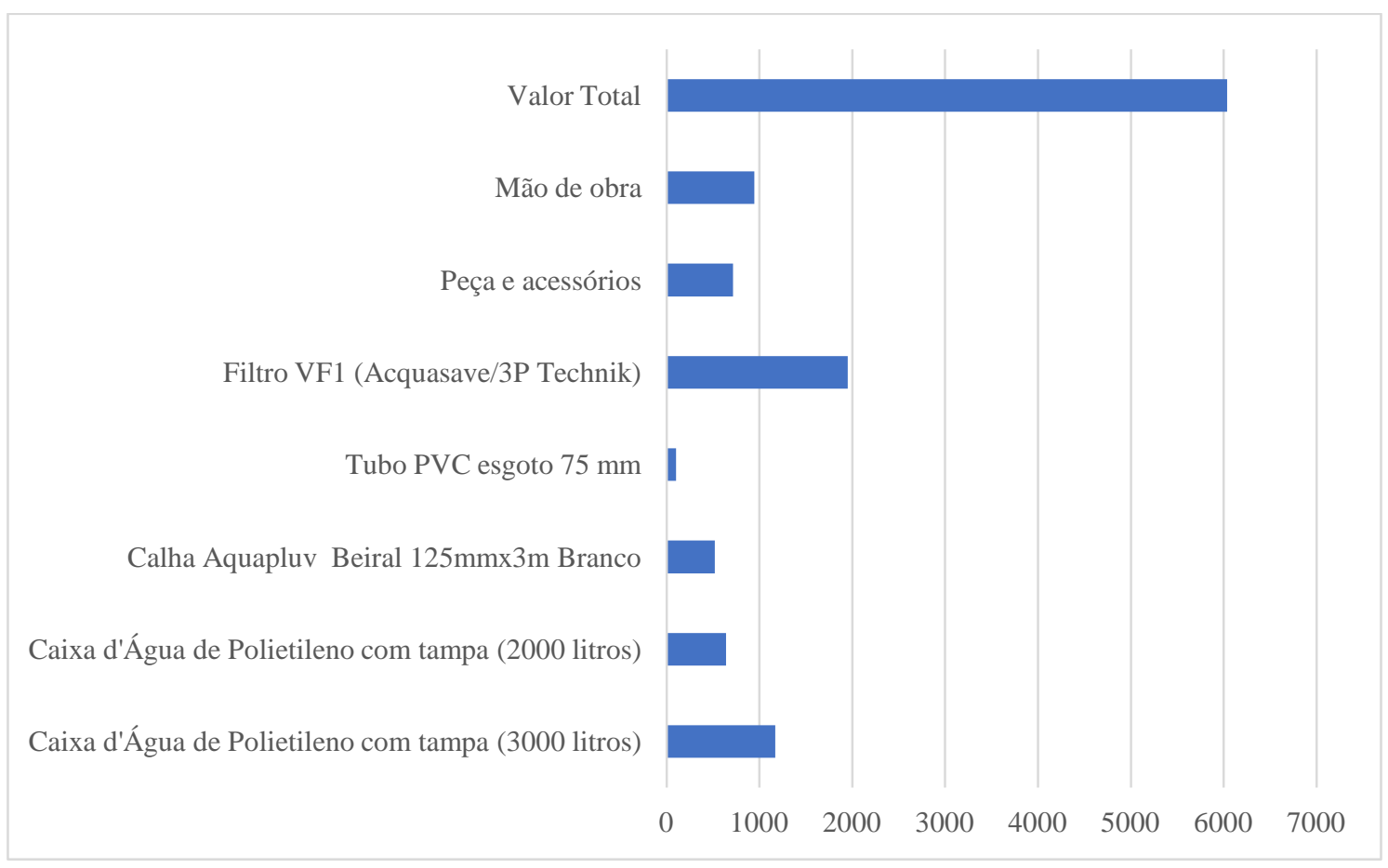

Figura 7. Custos dos materiais e total para instalação do sistema de reaproveitamento de água pluvial no telhado em estrutura metálica e telha de aço. 
Nota-se por meio de análise da Figura 7 que para o telhado em estrutura metálica e telha de aço o reservatório não foi o item de maior dispêndio. Este fato pode ser explicado pois, a exigência estrutural do reservatório de polietileno é diretamente proporcional ao volume do mesmo, que no caso foi dividido em dois reservatórios por não se encontrar comercialmente o volume encontrado no dimensionamento.

Conforme a Tabela 3 , são consumidos $73,84 \mathrm{~m}^{3}$ ano $^{-1}$ de água que pode ser substituída por água pluvial. 0 custo ao consumidor do metro cúbico de água em Formiga/MG é de $\mathrm{R} \$ 1,07$ desde que não exceda o gasto de $12 \mathrm{~m}^{3} \mathrm{mês}^{-1}$ (SAAE, 2015). Portanto, há uma economia de $\mathrm{R} \$ 79,01$ por ano tanto no telhado convencional de madeira, quanto no de estrutura metálica.

0 investimento no telhado convencional de madeira é de $\mathrm{R} \$ 19256,43$ obtendo o retorno em 244 anos. Já no telhado em estrutura metálica, o investimento é de $\mathrm{R} \$ 6037,98$ com o retorno em 74 anos e 4 meses.

Não foi viável calcular o retorno do investimento pelo Payback Descontado, pois é a maneira que se avalia o tempo de retorno com base não no seu fluxo de caixa gerado, mas sim no valor deste fluxo descontado a uma taxa mínima de atratividade.

Nota-se que esse tipo de projeto é economicamente inviável, visto que o valor de custo da água é relativamente barato, tanto no município de Formiga/MG quanto em outras localidades. Barbosa et al. (2017) encontraram em seu estudo um tempo de retorno do investimento de 43 anos, porém, o valor estabelecido pela concessionária responsável pela distribuição de água é de $\mathrm{R} \$ 5,48 / \mathrm{m}^{3}$. Este fato mostra que em localidades onde há uma cobrança maior pela água potável o sistema de aproveitamento de água pluvial tende a ser viável, principalmente para altas demandas.

\section{Conclusões}

Analisando a viabilidade técnica do aproveitamento da água pluvial para consumo não potável em edificações na cidade de Formiga/MG, contatou-se que com a implementação de sistemas para captação e reaproveitamento de águas pluviais em coberturas, é possível dar uma destinação mais adequada à água.

Empregando as diversas metodologias de dimensionamento, observou-se uma grande variação nos volumes dos reservatórios para as mesmas condições.

Os métodos que não levam a demanda em consideração em seus cálculos se mostraram mais propensos a gerar desabastecimento durante os meses secos. Em contrapartida os métodos que utilizam a demanda em seus cálculos apresentaram menores chances falharem em algum momento durante o abastecimento.

No telhado convencional em estrutura de madeira e telha cerâmica não é tecnicamente viável a instalação de um reservatório sob o telhado devido o alto volume encontrado. 0 reservatório poderia ser instalado no subterrâneo ou até na superfície, visto que o superficial poderia possuir a dimensão vertical consideravelmente maior do que a dimensão dos outros eixos, podendo não haver a necessidade de bombeamento, fato que teria que ser constatado por meio de uma análise de altura manométrica. Já o subterrâneo, necessitará de um sistema de bombeamento até um reservatório na parte superior da edificação, gerando gastos com energia elétrica. Entretanto, esse reservatório poderá apresentar um volume maior e com isso, suprir a demanda de água não potável mesmo nos períodos secos.

Já no telhado em estrutura metálica, o reservatório pode ser colocado sob a cobertura, desde que este não apresente um volume exacerbado. Porém, sendo ele um reservatório menor, 
em períodos de estiagem será necessário um realimentador com a água da rua para que não falte água, suprindo assim, a demanda total.

Em ambos os tipos de telhado, o sistema de aproveitamento de água pluvial não é economicamente viável, pois o metro cúbico da água no município analisado é relativamente barato e a implantação do sistema requer um grande investimento financeiro, com um retorno em longo prazo.

Porém, ao se analisar a viabilidade ambiental do investimento, o sistema de aproveitamento de água pluvial diminuiria os problemas de drenagem urbana, retendo boa parte da água que escoaria pelas ruas e galerias, e diminuiria também a quantidade de água tratada utilizada para fins não potáveis.

\section{Conflito de interesses}

Os autores declaram não haver conflito de interesses.

\section{Referências}

ABNT - Associação Brasileira de Normas Técnicas. ABNT NBR 10.844:1989 Instalações prediais de águas pluviais. Rio de Janeiro: ABNT, 1989.

ABNT - Associação Brasileira de Normas Técnicas. ABNT NBR 15.527:2007 - Água de chuva - Aproveitamento de coberturas em áreas urbanas para fins não potáveis Requisitos. Rio de Janeiro: ABNT, 2007.

ANA - Agência Nacional de Águas. Conjuntura dos recursos hídricos no Brasil: 2013. Brasília: ANA, 2013.

Amorim, S. V.; Pereira, D. J. A. Estudo comparativo dos métodos de dimensionamento para reservatórios utilizados em aproveitamento de água pluvial. Ambiente Construído, v. 8, p. 53-66, 2008.

Barbosa, R. K. R. C.; Cocco, G. P. R.; Almeida, G. H. L.; Lupp, L. S. L.; Bodevan, R. I.; Sales, V. S. L.; Jacob, R. S. Projeto de aproveitamento de água da chuva para o uso não potável domiciliar. Percurso Acadêmico, v. 7, n. 13, p. 42-73, 2017. https://doi.org/10.5752/ P.2236-0603.2017v7n13p42
Brandão, J. L. B.; Marcon, P. Análise dos métodos de dimensionamento de reservatório de águas pluviais sugeridos pela NBR 15227/07 com base na simulação diária. Engenharia Sanitária e Ambiental, v. 23, n. 6 , p. 1031-1041, 2018. https://doi.org/ $10.1590 / \mathrm{s} 1413-41522018129228$

Fendrich, R. Detenção distribuída e utilização das águas pluviais. Anais do XI Simpósio Nacional de Sistemas Prediais - SISPRED, Curitiba, Universidade Federal do Paraná, 2009.

Giacchini, M. Estudo quali-quantitativo do aproveitamento da água de chuva no contexto da sustentabilidade dos recursos hídricos. Curitiba: Universidade Federal do Paraná, 2010. (Dissertação de mestrado).

Gonçalves, R. F. (Coord). Consumo de água: uso racional da água em edificações. Rio de Janeiro: ABES, 2006.

Grupo de Pesquisa em Recursos Hídricos (DEA) - UFV. Plúvio 2.1: Software para determinação de parâmetros para equação de chuvas intensas. 2006.

IBGE - Instituto Brasileiro de Geografia e Estatística. Cidades. Formiga. Disponível em: <http://www.ibge.gov.br>. Acesso em: 03 abr. 2019.

Moruzzi, R. B.; Sousa Júnior, W. C.; Arduino, J.; Júlio, M. Avaliação do aproveitamento de água pluvial para atendimento de uso não potável no Aeroporto Internacional de São Paulo/Guarulhos. Engenharia Sanitária e Ambiental, v. 21, n. 1, p. 17-28, 2016. https://doi.org/10.1590/S1413-415202016 00100117248

Porto, R. M. Hidráulica básica. São Carlos: Editora EESC-USP, 2006.

Rupp, R. F.; Munarim, U.; Ghisi, E. Comparação de métodos para dimensionamento de reservatórios de água pluvial. Ambiente Construído, v. 11 p. 4764, 2011.

Sacadura, 0. M. Análise de sistemas de aproveitamento de água pluvial em edifícios. Lisboa: Universidade Nova de Lisboa, 2011. (Dissertação de mestrado).

SAAE - Serviço Autônomo de Água e Esgoto. Tarifas e valores. Formiga, MG. 2015. Disponível em: <http://www.saaeformiga. com.br/servicos/tarifas-e-valores>. Acesso em: 01 out. 2019. 
SINAPI - Sistema Nacional de Pesquisa de Custos e Índices da Construção Civil. Insumos. Manutenção de insumos caixa. Disponível em: <http://www.caixa.gov.br/ site/paginas/downloads.aspx\#categoria_738 >. Acesso em: 01 out. 2019.

Sperancetta, D.; Alves, J. V.; Krüger, C. M. Captação de águas pluviais para abastecimento residencial. da Vinci, v. 1, p. 29-42, 2004. Disponível em: <https://www.up.edu.br/davinci/pdf02.pdf> . Acesso em: 01 out. 2019.

TCPO. Tabelas de Composição de Preços para Orçamentos. 13. ed. São Paulo: Pini, 2013.

Informação da Licença: Este é um artigo Open Access distribuído sob os termos da Licença Creative Commons Attribution, que permite uso irrestrito, distribuição e reprodução em qualquer meio, desde que a obra original seja devidamente citada. 